\title{
THE SIMILARITY DEGREE OF APPROXIMATELY DIVISIBLE C*-ALGEBRAS
}

\begin{abstract}
WEIHUA LI
Abstract. Let $\mathscr{A}$ be a unital approximately divisible $\mathrm{C}^{*}$-algebra. We show that the similarity degree of $\mathscr{A}$ is at most 5 .

Mathematics subject classification (2010): Primary 46L05.

Keywords and phrases: Approximately divisible $\mathrm{C}^{*}$-algebra, similarity degree, subrank.
\end{abstract}

\section{REFERENCES}

[1] B. BLACKADAR, A. KUMJIAN AND M. RøRDAM, Approximately central matrix units and the structure of noncommutative tori, K-theory 6 (1992), 267-284.

[2] J. W. BunCE, The similarity problem for representations of $C^{*}$-algebras, Proc. Amer. Math. Soc. 81 (1981), 409-414.

[3] E. Christensen, Extensions of derivations II, Math. Scand. 50 (1982), 111-122.

[4] E. Christensen, Finite von Neumann algebra factors with property $\Gamma$, J. Funct. Anal. 186 (2001), $366-380$.

[5] U. HAagerup, Solution of the similarity problem for cyclic representations of $C^{*}$-algebras, Ann. Math. 118 (1983), 215-240.

[6] R. KADISOn, On the orthogonalization of operator representations, Amer. J. Math. 77 (1955), 600622.

[7] W. Li AND J. SHEN, A note on approximately divisible $C^{*}$-algebras, preprint, arXiv 0804.0465.

[8] G. PISIER, The similarity degree of an operator algebra, St. Petersburg Math. J. 10 (1999), 103-146.

[9] G. PISIER, Remarks on the similarity degree of an operator algebra, Internat. J. Math. 12 (2001), 403-414.

[10] G. PISIER, Similarity problems and length, Taiwanese J. Math. 5 (2001), 1-17.

[11] G. PISIER, A similarity degree characterization of nuclear $C^{*}$-algebras, Publ. Res. Inst. Math. Sci. 42, 3 (2006), 691-704.

[12] F. Pop, The similarity problem for tensor products of certain $C^{*}$-algebras, Bull. Austral. Math. Soc. 70 (2004), 385-389. 